\title{
Scientific Opportunities for Heterogeneous Catalysis Research at the SuperXAS and SNBL Beam Lines
}

\author{
Paula M. Abdalaa, Olga V. Safonova ${ }^{* b}$, Geir Wikera, Wouter van Beek, Herman Emerich ${ }^{\mathrm{a}}$, \\ Jeroen A. van Bokhoven ${ }^{\text {bc }}$, Jacinto Sáb, Jakub Szlachetko ${ }^{\mathrm{b}}$, and Maarten Nachtegaal ${ }^{\mathrm{b}}$
}

\begin{abstract}
In this short review, we describe the complementary experimental capabilities for catalysis research at two beam lines available to the Swiss community, SuperXAS at SLS (Swiss Light Source, Villigen) and SNBL (Swiss Norwegian Beam lines) at ESRF (European Synchrotron Radiation Facility, Grenoble). Over the years, these two facilities have been developed to provide powerful techniques for structural studies under in situ and operando conditions. These techniques, X-ray diffraction (XRD), X-ray absorption spectroscopy (XAS), and X-ray emission spectroscopy (XES) in combination with Raman or infrared spectroscopy provide new avenues for structure-performance studies of catalysts. Several exemplary studies are used to demonstrate the capability of these facilities.
\end{abstract}

Keywords: Catalysis · Synchrotron radiation · X-ray absorption and emission spectroscopy .

$\mathrm{X}$-ray powder diffraction

\section{Introduction}

Contemporary catalysis research aims at developing new technology for clean energy, chemicals production and exhaust gas treatment. The progress in the design of new catalysts and the improvements of catalytic processes relies on understanding the structure-performance relationship. Synchrotron-based techniques are powerful tools for the structural studies of heterogeneous and homogeneous catalysts providing detailed insight into the structure of complex systems. ${ }^{[1-5]}$ They can be applied under reaction conditions to obtain crucial information on the structure of the active sites, uncover reaction mechanisms and reasons for catalyst deactivation. A better understanding of the structure-per-

\footnotetext{
${ }^{\star}$ Correspondence: Dr. O. V. Safonova

Tel.: +4156310 5805

Fax: +4156310 3151

E-mail: olga.safonova@psi.ch

aSwiss-Norwegian Beam lines at ESRF

6 Rue Jules Horowitz

F38043 Grenoble

bPaul Scherrer Institut, CH-5232 Villigen PSI

Institute for Chemical and Bioengineering

ETH Zurich, $\mathrm{CH}-8093$ Zürich
}

formance relationship can lead to improvements in the activity, selectivity, and stability of the catalysts as demonstrated in several studies reviewed in the literature. ${ }^{[6]}$

Among synchrotron methods, XAS and XRD are the most common tools for structural characterization of catalysts. $\mathrm{XRD}$ is sensitive to the long range order and provides valuable information on the nature of crystalline phases and their microstructure. In contrast, X-ray absorption methods, such as X-ray absorption nearedge structure (XANES) and extended $\mathrm{X}$-ray absorption fine structure (EXAFS) spectroscopy, are element-specific and sensitive to the short range order in crystalline and amorphous solids as well as species in the liquid phase. These methods allow characterization of the chemical state and local environment of the active species, promoters, and poisoning elements in the catalysts. EXAFS can also be used to estimate the average size of supported metal clusters with sizes below 4 $\mathrm{nm}$, which are invisible to XRD. X-ray emission spectroscopy (XES) has recently become available at third-generation synchrotrons. ${ }^{[7]}$ In contrast to XANES, which reflects the density of unoccupied states, XES probes the density of occupied states providing complementary information on the electronic structure of the element of interest. The complementarities between these methods and the advantages of combining them to obtain a complete structural view have been widely discussed. ${ }^{[3,8,9]}$

Since hard X-rays can penetrate through the sample, its environment and the window material, XRD, XAS and XES are especially well-suited for in situ and operando characterization of catalysts. Thus, important structural information can be gained under working conditions of catalysts with setups similar to those used in the academic and industrial laboratories. Due to the dynamic changes in the catalyst structure during reaction, time-resolved characterization is also essential to understand the interplay between structure and activity. Therefore, the development of time-resolved methods and multi-technique approaches providing complimentary information is critical for the advance of catalytic science. $[1,3,10,11]$

In this article, we review the stateof-the-art research tools available at synchrotrons for catalytic science based on experiments performed at the SNBL and SuperXAS beam lines. These two facilities share a common purpose and they provide the users with highly complementary techniques. The technical features of each facility will be discussed in detail focusing on catalytic applications. Due to a close interaction between the catalysis community and the beam line scientists, these beam lines are continuously upgraded with a focal point in catalysts research. The most recent improvements are:

i) Faster data acquisition to perform time-resolved experiments.

ii) Combination of different synchrotron- and non-synchrotron-based techniques in a single experiment.

ii) Development of specific cells for in situ and operando experiments. 
Table 1. The main characteristics of SNBL-BM01B and SuperXAS beam lines

\section{Beam line}

Monochromator

Si (111) CCM

SNBL-BM01B

Techniques
Energy range
Detectors

Time resolution
(continuous scans)
Time resolution
(step mode)

Sample environments

Other characterization techniques available
$6 \mathrm{Si}(111)$ analyzer/ scintillation detectors

Minutes $^{\mathrm{a}}$

$-$
Si (111) DCM

XAS

$5-80.7 \mathrm{keV}$

Ion chambers, 13-element Ge detector, 1-element Si drift detector

5 to $300 \mathrm{~s}$

10 to $60 \mathrm{~min}$

Plug flow reactors Gas mixing system (up to 20 bar). Gas blower oven (up to $1173 \mathrm{~K}$ ) Cryo-stream (100-300 K)

Raman spectroscopy Mass spectrometry
SuperXAS

$$
\text { Si (111) and Si(311) DCM }
$$

$\mathrm{Si}(111)$

Si(311) CCM

XES

XAS

HERFD XAS
RIXS

XAS

$4.5-15$

$5.5-26$

Ion chambers,

PIPS diode,

13-element

Ge detector,

1-element Si

drift detector

Johann and
von Hamos chambers,
PIPS diode

spectrometers

$$
5 \text { to } 300 \mathrm{~s}
$$

0.03 to $5 \mathrm{~s}$

10 to $60 \mathrm{~min}$

$$
1 \mathrm{~s}-1 \mathrm{~h}
$$

Plug flow reactors Gas mixing system

Gas blower oven (up to $1173 \mathrm{~K}$ )

Cryo-stream (100-300 K)

Infra-red spectroscopy

Mass spectrometry and micro gas chromatography

${ }^{a} \mathrm{~A}$ few seconds in the near future (fast XRD area detector).

Table 1 summarizes the main characteristics of both beam lines.

\section{Combining XAS/XRD/Raman at SNBL}

The SNBL at the ESRF is composed of two experimental stations (BM01A and BM01B) that run simultaneously. Here, we will outline the beam line capabilities of the B station -BM01B- focusing on heterogeneous catalysis applications. Details about station BM01A can be found in ref. [12].

BM01B is dedicated to high-resolution powder diffraction (HRPD) and XAS experiments. Both techniques can be performed independently and quasi-simultaneously during the same experiment. In addition, Raman spectroscopy can be run in parallel. ${ }^{[10]}$ Fig. 1a shows the BM01B scheme. It is equipped with dedicated monochromators for each technique: a channel cut monochromator (CCM) for diffraction and a double crystal monochromator (DCM) for XAS experiments. The monochromators can be automatically and rapidly moved in and out of the beam, allowing consecutive XRD and XAS scans under optimal conditions for each technique.

The XAS monochromator can work either in step mode, or in continuous mode, for quick XANES measurements (XANES spectrum can be acquired in 5-100 s and a complete EXAFS spectrum in 1-5 minutes). It was designed to provide a wide energy range spanning from the K-edge of titanium $(4.966 \mathrm{keV})$ to the gold K-edge at $80.725 \mathrm{keV}$. XAS measurements can be performed in transmission or in fluo-

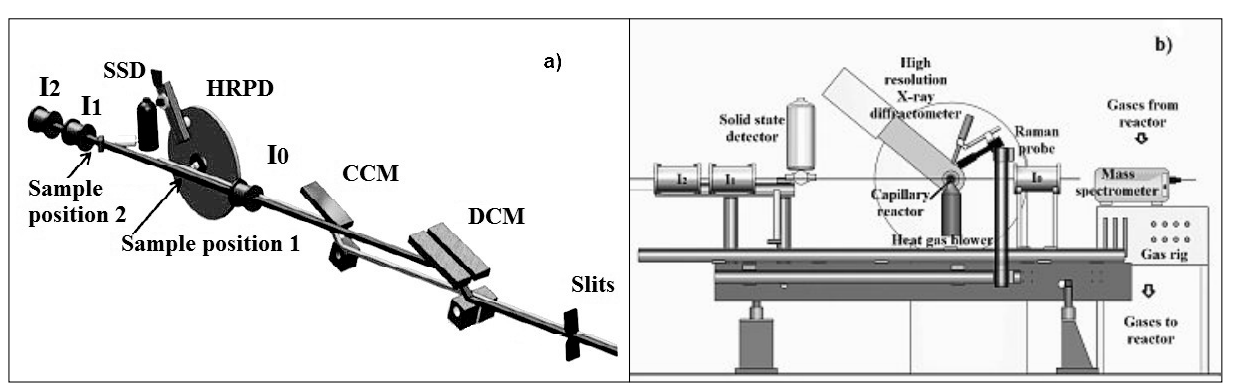

Fig. 1. a) Schematic layout of the optic of SNBL-BM01B beam line ${ }^{[10]}$ with permission of Taylor \& Francis Ltd., b) SNBL-BM01B setup for a combined XRD/XAS/Raman in situ experiment. rescence mode by using a 13-element solid-state detector (Canberra) or a single element silicon drift detector (Vortex) for quick scans.

The diffractometer is equipped with a six-detector/analyzer system resulting in an intrinsic resolution (FWHM) of about 0.01 degrees at a wavelength of $0.5 \AA$. It is normally operated in a continuous scan mode. In the near future a large area detector will become available for faster time resolved XRD (achieving similar time resolution to the XAS scans).

Many investigations underline the importance of using complementary techniques which provide long-range information about the crystallographic structure in conjunction with a local atomic structure probe, such as XRD and XAS. Raman spectroscopy has the ability to probe the 'length scale' intermediate between these two extremes using vibrational information. ${ }^{[3,10,13]}$ Therefore, the experimental station has been equipped with a specially designed remote Raman probe connected to a Renishaw inVia spectrometer, allowing in situ Raman spectroscopy in parallel with the existing X-ray techniques. ${ }^{[10,13]}$ Further information about the optic details and design of the beam line can be found elsewhere. ${ }^{[10,14]}$

This multi-technique approach has shown its versatility in several domains of science; and in recent years, special attention has been paid to specific requirements 
for catalysts studies. ${ }^{[14]}$ Many outstanding research projects in the field of heterogeneous catalysis involving XAS, XRD and combined experiments under static and operando conditions have been carried out.

Key to determining structure-performance relations is reproducing the working conditions that are relevant for catalysis at the beam line. This is a challenging task. The specialized instrumentation available at SNBL allows scientists to reproduce specific environments. Depending on the experiment, different in situ cells are available. ${ }^{[10,15-17]}$ In particular, a homemade capillary flow reactor cell supported on stainless steel brackets has been extensively used for in situ and operando experiments at SNBL. This cell is connected to a gas mixing system while the gaseous products of the reaction can be monitored by an on-line mass spectrometer (MS). See Fig. $1 \mathrm{~b}$ for details of the combined experiment set-up. Hot air blowers and cryo-streamers are used to control the temperature in the capillary reactor cell. With this setup, the temperature can be controlled in the range of about 77 to $1173 \mathrm{~K}$ and the gas system provides pressures up to 20 bars.

The availability of XRD, XAS and Raman spectroscopy at the same sample position has many advantages and provides unique opportunities to the user to reveal structural aspects of catalysts. Some selected examples below illustrate the capabilities of SNBL and how they provide insight into the structure of heterogeneous catalysts.

In the past years, different studies have been focused on the Fischer Tropsch synthesis (FTS) with catalysts under industrial conditions. ${ }^{[14,18]}$ In a FTS process, syngas, a mixture of $\mathrm{CO}$ and $\mathrm{H}_{2}$, is converted into paraffins of varying length. As an example on this relevant topic, we briefly discuss an investigation by Ronning et al. ${ }^{[18]}$ using complementary techniques. These authors combined XRD and XANES to reveal the crystallite size and the oxidation states of the active component in a cobalt-based catalyst for FTS while monitoring methane formation by mass spectrometry. XRD and XAS showed structural changes occurring during thermal reduction and reaction. Figs $2 a$ and $2 b$ show the evolution of XANES spectra and XRD diffractograms from the $\mathrm{Co}_{3} \mathrm{O}_{4}$ spinel structure of the freshly produced catalyst via the metastable $\mathrm{CoO}$ to the formation of Co during thermal reduction. The X-ray line broadening analysis, using the Scherrer equation, showed that the metallic cobalt crystallites after reduction were reduced in size compared to the initial phase. The XANES data showed that cobalt oxide was not completely reduced: with about $10 \%$ of the cobalt remaining in the non-metallic phase after reduction. Moreover, the experiment under

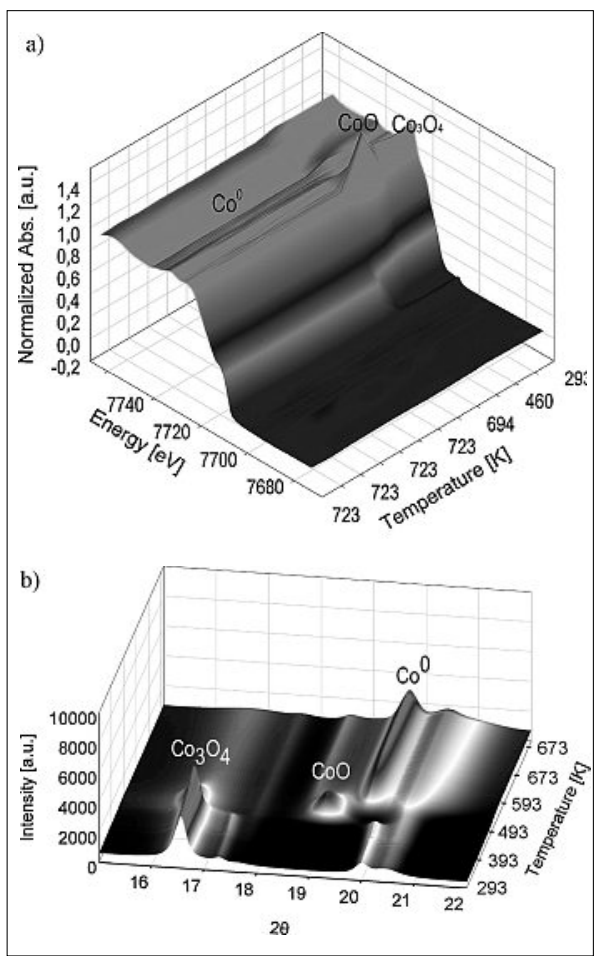

Fig. 2. Illustrative in situ XANES (a) and XRD (b) data collected during reduction of the cobaltbased catalyst for FTS. Reprinted from ref. [18] with permission from Elsevier.

FTS performed under different conditions revealed that at $483 \mathrm{~K}$ no significant sintering and no change in Co state occurred during the initial stage of the reaction, while at $673 \mathrm{~K}$ and under methanation conditions, cobalt crystallite particle growth and further reduction of cobalt were observed. The importance of determining the redox conditions and the crystallite size evolution under the operando conditions relies on the fact that re-oxidation and sintering have been proposed as possible deactivation mechanisms. This study emphasized both the importance of performing X-ray based experiments under industrial conditions and the advantage of combining different techniques, especially when multiple mechanisms are involved.

The following example deals with the total oxidation of methane over a $\mathrm{Pd} /$

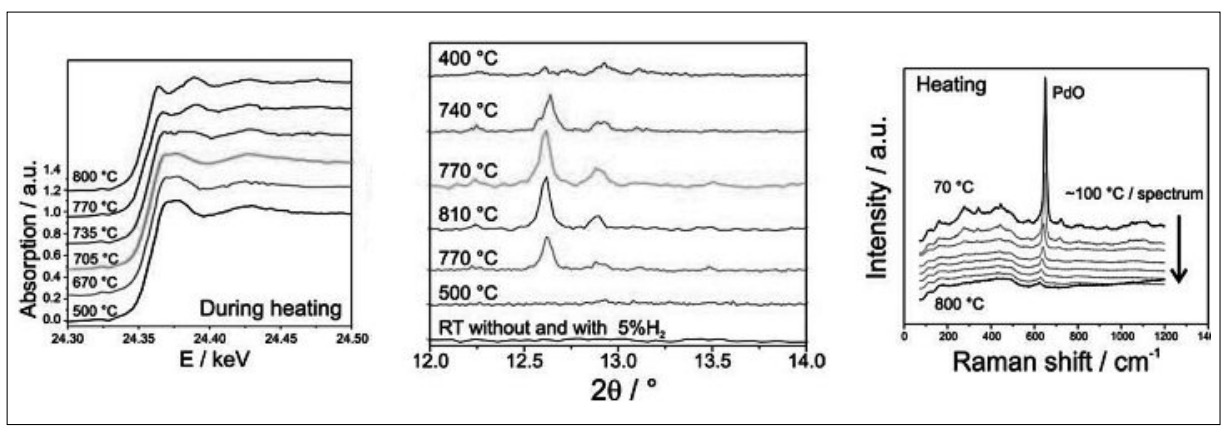

Fig. 3. Total oxidation of methane over a $\mathrm{Pd} / \mathrm{ZrO}_{2}$ catalyst. In situ XANES spectra during the first heating cycle (a); XRD data during the first heating-cooling cycle and (b) Raman spectra during heating in the second cycle (c). Reproduced from ref. [19] with permission from IOP Publishing.
$\mathrm{ZrO}$ catalyst. In order to investigate the catalyst structure-performance relationship, Grunwaldt et al. ${ }^{[19,20]}$ carried out a combined XAS/XRD/Raman experiment under reaction conditions with on-line analysis of the gas composition. The shortand long-range order information of the palladium phase was obtained. According to XAS, the palladium constituent in the as-prepared sample was mainly oxidized. However, the presence of $\mathrm{PdO}$ was not detected by XRD and no or only a weak Raman band at $650 \mathrm{~cm}^{-1}$ typical for $\mathrm{PdO}$ was observed, revealing that palladium oxide was well dispersed in the as-prepared samples. In situ consecutive heating-cooling studies evidenced a direct correlation between Pd oxidation state, particle sintering and the performance of the catalyst. A strong deactivation was observed during thermal reduction. At the same time, XANES indicated reduction and XRD sintering of the Pd particles, while no changes were observed by Raman. Figs $3 a$ and $3 b$ show the XANES and XRD measurements in the first heating-cooling cycle. During cooling, the characteristic PdO Raman band appeared. Fig. 3c shows the Raman spectra measured on heating in the second cycle. Interestingly, no $\mathrm{PdO}$ reflections were observed in simultaneously recorded XRD patterns, indicating that the crystallite size was still too small to create detectable diffraction. This study demonstrated that the state of the metal and its dispersion both play an important role in the deactivation of the catalyst, where highly dispersed oxidized palladium seems to be best for catalytic conversion of methane. Besides, it illustrates how the employed techniques provide information on the different length scales.

Finally, we have chosen a work by Deka et al. ${ }^{[21]}$ reporting insight into the nature of the active species in copper-exchanged zeolites for selective catalytic reduction (SCR) using $\mathrm{NH}_{3}$. $\mathrm{NH}_{3}-\mathrm{SCR}$ is a widely used technology for $\mathrm{NO}_{x}$ reduction in diesel after-treatment systems. Cu-SSZ-13 zeolite has attracted great attention due to its excellent activity and hydrothermal sta- 
bility for this reaction. The local environment of the copper species in the catalyst is crucial for the catalytic process. This study combined in situ EXAFS, XANES, and XRD data to provide complementary information on the copper local structure under realistic conditions.

The analysis of these data indicated that isolated mononuclear $\mathrm{Cu}^{2+}$ species located on the plane and slightly distorted from the centre of double-6-ring subunits are the active sites of the zeolites. This $\mathrm{Cu}^{2+}$ position remained under operando SCR conditions (at $300{ }^{\circ} \mathrm{C}$ ). A conformational change from a square planar to a distorted tetrahedral type environment as a result of a direct interaction of $\mathrm{NH}_{3}$ with copper was seen at intermediate temperatures $\left(125^{\circ} \mathrm{C}\right)$. Although this process is an essential step in the mechanism, it causes decrease of activity at low temperatures. The change in the coordination geometry at higher temperatures was concurrent with the maximum catalytic activity. This study clearly exemplifies the advantage of combining laboratory- and synchrotron-based techniques to elucidate the origin of the activity in industrially relevant and complex catalysts, by determining the location of the active site, its coordination geometry and its redox functionality.

\section{Enhanced Time- and Energy- resolution at the SuperXAS Beam Line}

SuperXAS is a dedicated beam line for X-ray spectroscopic studies of different types of functional materials and in particular for in situ studies of catalysts. ${ }^{[22]}$ XAS and XES provide element-specific information of the electronic and geometric structure of a selected component of a catalyst. The use of hard X-rays allows in situ studies in specially designed reactors. An important requirement for in situ studies is fast data acquisition in order to access the dynamic changes in the materials under working conditions ( $\mathrm{T}=100-1173$ $\mathrm{K}, \mathrm{p}=1-400$ bar). The SuperXAS beam line provides the user community with several scanning modes that allow the chemical kinetics to be followed, where the fastest scanning mode requires $100 \mathrm{~ms}$ per full EXAFS spectrum. In addition, a wide range of detectors is available at the SuperXAS beam line, including two highenergy-resolution emission (fluorescence) spectrometers with eV energy resolution.

The SLS is a third-generation synchrotron, which operates under top up mode, $2.4 \mathrm{GeV}$ electron energy, and a current of $400 \mathrm{~mA}$. The SuperXAS beam line is positioned on one of three superbend ports and provides photons over an energy range between 4.5 and $36 \mathrm{keV}$. The main opti-

Table 2. Characteristics of detectors used at SuperXAS

\begin{tabular}{|l|l|l|l|l|l|}
$\begin{array}{l}\text { Type of } \\
\text { detector }\end{array}$ & $\begin{array}{l}\text { Detection } \\
\text { mode }\end{array}$ & $\begin{array}{l}\text { Energy } \\
\text { resolution }\end{array}$ & $\begin{array}{l}\text { DCM } \\
\text { step mode }\end{array}$ & $\begin{array}{l}\text { DCM } \\
\text { continuous }\end{array}$ & QEXAFS \\
\hline $\begin{array}{l}\text { Ion chambers } \\
\text { transmission }\end{array}$ & low & + & + & + \\
\hline $\begin{array}{l}\text { Large area } \\
\text { Si diode }\end{array}$ & $\begin{array}{l}\text { fluorescence/ } \\
\text { transmission }\end{array}$ & low & + & + & + \\
\hline $\begin{array}{l}13 \text { element } \\
\text { Ge detector }\end{array}$ & fluorescence & $\begin{array}{l}\text { middle } \\
(>150 \mathrm{eV})\end{array}$ & + & - & - \\
\hline $\begin{array}{l}1 \text { element } \\
\text { Ketek }\end{array}$ & fluorescence & $\begin{array}{l}\text { middle } \\
(>150 \mathrm{eV})\end{array}$ & + & + & - \\
\hline $\begin{array}{l}\text { 5-crystal } \\
\text { Johann }\end{array}$ & fluorescence & $\begin{array}{l}\text { high } \\
(\sim 1 \mathrm{eV})\end{array}$ & + & + & - \\
\hline $\begin{array}{l}\text { 3-crystal von } \\
\text { Hamos }\end{array}$ & fluorescence & $\begin{array}{l}\text { high } \\
(\sim 1 \mathrm{eV})\end{array}$ & + & + & + \\
\hline
\end{tabular}

cal components are: vertically collimating mirror, DCM, CCM for quick-EXAFS (QEXAFS) and a toroidal focusing mirror. More details on the beam line layout can be found in ref. [22] The DCM can be either moved in step scanning mode that ensures a high beam position stability or continuously that allows faster scans (in this mode one typically obtains full EXAFS in 1-5 minutes and XANES in 5-30 s). For faster data acquisition, a channel-cut QEXAFS monochromator is available that allows the acquisition of a full EXAFS spectrum with a repetition rate of $1-10 \mathrm{~Hz}(0.1-5 \mathrm{~s}$ per spectrum) and XANES with $1-15 \mathrm{~Hz}$ (0.03-1 s per spectrum). The toroidal mirror ensures a focused photon flux over the complete energy range with a minimal spot size of $100 \times 100$ micrometers at different positions in the experimental hutch.

Samples can be measured in both transmission and fluorescence mode and the main detectors are summarized in Table 2. For emission (fluorescence) spectroscopy with a higher energy resolution $(0.5-2 \mathrm{eV})$ a 5-crystal X-ray emission spectrometer in vertical Johann geometry ${ }^{[23,24]}$ and a 3-crystal in the vertical von Hamos geometry ${ }^{[25]}$ have been constructed. In the Johann geometry, spherically bent analyzers ( $\mathrm{Si}$ and $\mathrm{Ge}$ ) allow monochromatization of the fluorescence energy and focusing on the Pilatus 100k detector. [26] This spectrometer is efficiently used for high-energy-resolution fluorescence detected (HERFD) XANES, [7,27] Fig. 4 compares a HERFD XAS spectrum with one detected in transmission mode, illustrating the enhanced spectral resolution of the data. The von Hamos-type spectrometer allows a full emission spectrum (100-200 eV) to be collected in a single shot without moving any optical element. Here, X-ray fluorescence is diffracted by cylindrically bent analyzer crystals ( $\mathrm{Si}$ and Ge wafers) and a 1D-array, single photon counting, MythenII detector is employed. [28] This spectrometer is used for the detection of the fine structure of X-ray emission lines (XES), including valence-to-core transitions, and resonant inelastic X-ray scattering (RIXS). These techniques are highly complementary to XAS providing additional information on the electronic and geometric structure of a specific element with enhanced chemical sensitivity. Fig. 5a shows an example of a 1s3p RIXS map of $\mathrm{CuO}$. To measure this map, the incident energy of the DCM was scanned across the $\mathrm{Cu}$ K-edge while the resonant emission spectrum was collected around the $\mathrm{K} \beta$ emission lines. Fig. $5 \mathrm{~b}$ presents an example of the valence-to-core XES spectra of $\mathrm{CuO}$ corresponding to the p-projected occupied electronic states.

For in situ studies, the SuperXAS beam line is equipped with a dedicated gas infrastructure, all necessary gas leak detectors, a gas manifold system, mass spectrometer and several reactor cells ${ }^{[10,15,29,30]}$ available for expert users. Recently, a Bruker V70 infra-red (IR) spectrometer was installed at the beam line and a setup for combined XAS/XES-IR experiments is currently being commissioned. The main advantage of combining XAS/XES and IR spectroscopy in the same setup is the possibility to follow the changes in the electronic and geometric structure of metals (via XAS/XES)

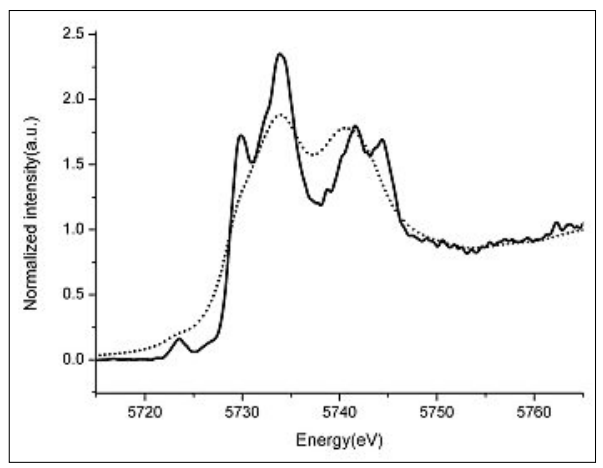

Fig. 4. $\mathrm{Ce}_{3}$ edge HERFD XANES (solid line) of $\mathrm{CeO}_{2}$ measured using $\mathrm{L} \alpha 1$ emission line and the corresponding XANES spectrum measured in transmission mode (dotted line). 


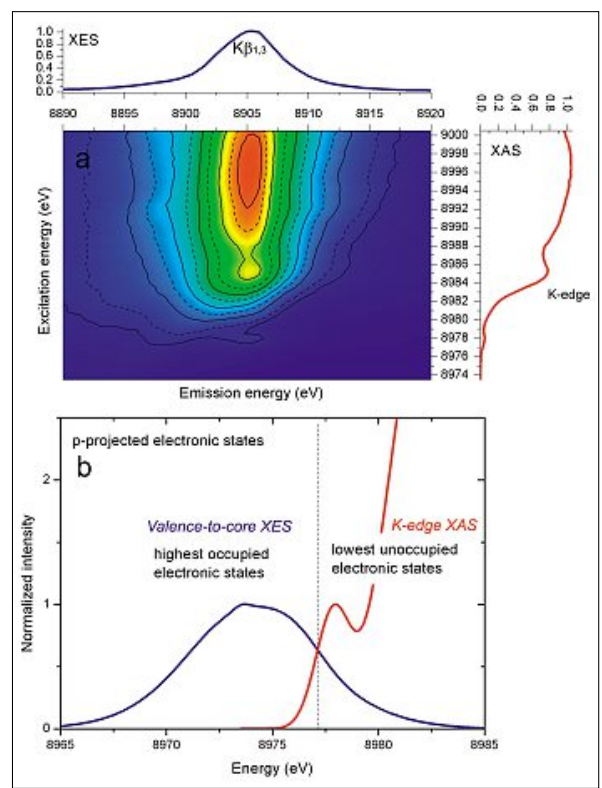

Fig. 5. a) 1s3p RIXS map of CuO: the projection on the top and on the right side show the XES and XAS spectra, respectively. b) Valenceto-core XES spectra ( $\mathrm{K} \beta$ satellite lines) of $\mathrm{CuO}$ providing complementary information to the $\mathrm{Cu}$ K-edge XAS.

and simultaneously getting information on the nature of adsorbed species (via IR spectroscopy). The current status of combined XAS/IR setups for catalytic research has been reviewed previously. ${ }^{[3]}$

The following examples from recent experiments conducted at SuperXAS illustrate the main beam line features with respect to time resolution, high energy resolution XES/XAS and dedicated in situ setups.

A spatially and time-resolved QEXAFS study $\left(100 \times 100 \mu^{2}\right.$-sized beam, 2 spectra per $1 \mathrm{~s}$ ) at the $\mathrm{Pt}_{3}$ - edge was performed to follow the state of the catalyst during the rapidly oscillating $\mathrm{CO}$ oxidation on an industrial catalyst $\left(2 \mathrm{wt} \% \mathrm{Pt}\right.$ on $\gamma-\mathrm{Al}_{2} \mathrm{O}_{3}$ ) at different positions within a plug flow reactor. [31] $\mathrm{CO}$ conversion was achieved by heating a mixture of $\mathrm{CO}$ and $\mathrm{O}_{2}(19: 1)$ up to 398 K. Full conversion was obtained at this temperature as can be seen in Fig. 6a where the mass spectrometer signals are plotted as a function of temperature. Upon decreasing temperature, small oscillations in $\mathrm{CO}_{2}$ conversion were observed in the mass spectrometer traces of reactants and products. The reaction extinguished at $\mathrm{ca} .377$ $\mathrm{K}$. Also shown in Fig. 6a is the maximum intensity of the Pt whiteline of each quick XAS spectrum, collected $1 \mathrm{~mm}$ below the inlet of the plug flow reactor. Full EXAFS analysis at each point indicated that high intensity of the Pt whiteline corresponded to partially oxidized platinum, whereas low intensity indicated fully reduced platinum particles. When $\mathrm{CO}$ conversion decreased, oxidized Pt was converted to reduced Pt, suggesting that partially oxidized
$\mathrm{Pt}$ is the more active phase. In addition to the reduction of the catalyst during extinction, oscillations in the whiteline intensity can also be observed. Fig. $6 \mathrm{~b}$ shows that most of the spectra collected during the few oscillations can be well described by a combination of spectra of surface-oxidized $\mathrm{Pt}$ and $\mathrm{CO}$ covered reduced Pt. Within an oscillation, the initial loss of activity was accompanied by an increased amount of $\mathrm{CO}$-covered surface at the expense of the surface-oxidized platinum. During the sharp rise and excess formation of $\mathrm{CO}_{2}$, the linear combination fit showed misfits, which suggests that surface oxidized and CO-covered surface are not the only components during this part of the oscillation. Comparing two spectra with identical white line intensity (Fig. 6b, inset) showed a small shift in energy, which is characteristic of the difference between bare surface and surface with adsorbed CO. These linear combination fits provide evidence that after freeing the surface of $\mathrm{CO}$, there exist sites for dissociative $\mathrm{O}_{2}$ adsorption. In summary, these QEXAFS studies showed the dynamic structure of a technical catalyst within a plug flow reactor as function of time and position within the reactor and identified the relation between structure and activity.

In the work of Reimann et al. [32] QEXAFS was used to gain insight in the mechanism of Heck-type $\mathrm{C}-\mathrm{C}$ coupling reactions in the presence of supported $\mathrm{Pd}-$ based catalysts. Using a specially designed in situ cell, both the solid catalyst and the liquid reaction mixture during the reaction of phenyl bromide ( $\mathrm{PhBr}$ ) with styrene were monitored. Soluble Pd species were rapidly detected in the liquid reaction phase once the reaction temperature of $150{ }^{\circ} \mathrm{C}$ was reached. At the same time, the conversion of $\mathrm{PhBr}$ started. When the conversion was high the 'active phase' of the catalyst hardly changed according to
EXAFS and XANES and was identified as colloidal $\mathrm{Pd}^{\circ}$ clusters with a size of about $2 \mathrm{~nm}$. When the reaction rate started to decrease, pronounced changes in the EXAFS spectra of Pd were observed, which were attributed to an increased formation of bromo-palladates $\left(\left[\mathrm{PdBr}_{4}\right]^{2-},\left[\mathrm{Pd}_{2} \mathrm{Br}_{6}\right]^{2-}\right)$. In addition to the liquid-phase, significant changes were observed in the solid catalyst that was also probed in situ during the reaction. The originally oxidized Pd catalyst was efficiently reduced upon heating and then the sintering of the Pd particles was observed by both in situ EXAFS and STEM. The results confirmed the crucial role of the soluble molecular Pd complexes as the catalytically active species and clarified their relation to the in situ formation of Pd colloids. This work demonstrates the potential of QEXAFS for gaining deeper insight into the mechanism of such complex industrially important systems under relevant reaction conditions thanks to the targeted design of the in situ cell.

The enhanced sensitivity of HERFD XANES to the electronic and geometric structure of materials was demonstrated in the work of Paun et al. ${ }^{[33]}$ The HERFD XANES at the $\mathrm{Ce}_{3}$ edge allowed the differences in structure of ceria $\left(\mathrm{CeO}_{2}\right)$ nanoparticles as a function of size to be visualized, which were not accessible by conventional XANES (Fig. 7). The importance of ceria in catalysis originates from its exceptional oxygen storage or buffering capacity. It allows ceria to perform oxidation reactions, even in the absence of oxygen in the atmosphere. The differences indicated enhanced structural disorder of the nanoparticles surfaces, which was corroborated by complementary XRD and $\mathrm{Ce}$ K-edge EXAFS data obtained at SNBL on the same samples, and which can possibly explain the enhanced oxygen mobility and oxygen storage capacity of nanoparticles compared to the bulk structure. Moreover,

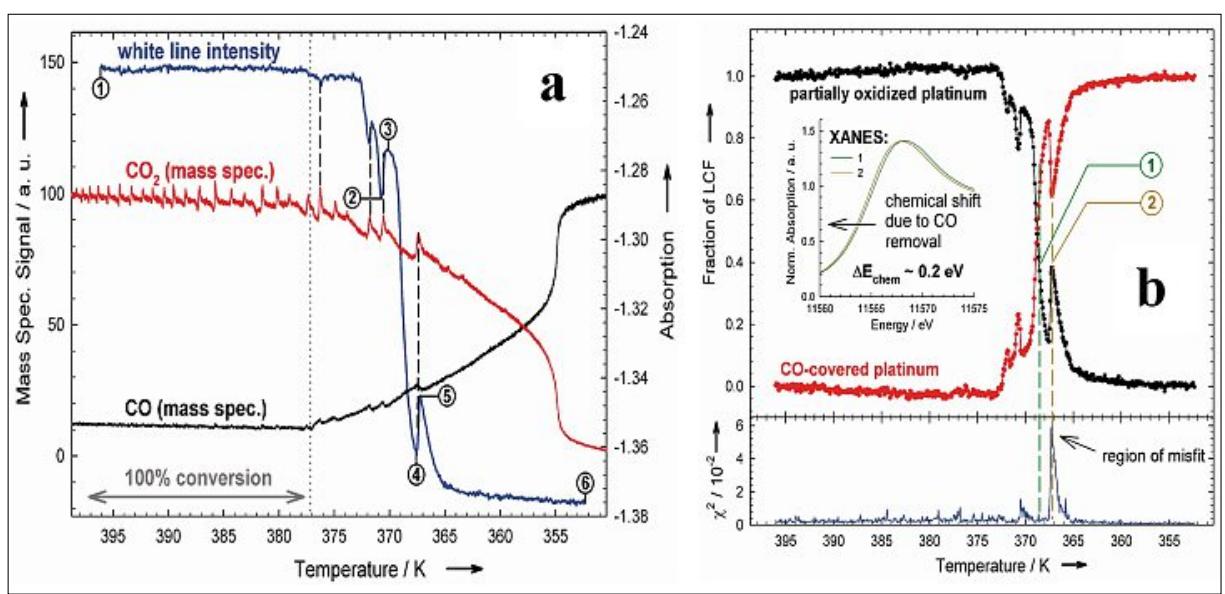

Fig. 6. a) The white line intensity of the $\mathrm{Pt}_{\mathrm{B}}$ edge spectra measured one millimeter below the top of a plug-flow reactor during the oscillations of $\mathrm{CO}$ oxidation as a function of temperature over 2 wt $\% \mathrm{Pt} / \mathrm{Al}_{2} \mathrm{O}_{3}$. b) Linear combination fitting of the XANES spectra in a). Reproduced from ref. [31] with permission of Wiley-VCH. 
the precise determination of the cerium oxidation state using Ce K-edge HERFD XANES indicated no relation between the oxidation state of cerium and the size of ceria nanoparticles, which was suggested by previous work based on in vacuum XPS studies. The second example of high energy resolution spectroscopy concerns the catalytic process of nitrites removal from drinking water by catalytic reduction (by hydrogen) on supported bimetallic nanoparticles ( $\mathrm{Pt}-\mathrm{Cu}$ and $\mathrm{Pd}-\mathrm{Cu}){ }^{[34]}$ The setup consisted of a kapton capillary reactor where the catalyst powder was fixed with quartz wool plugs. The catalysts were reduced in situ for $1 \mathrm{~h}$ under flow of pure $\mathrm{H}_{2}$ at $300{ }^{\circ} \mathrm{C}$. After reduction, the catalyst was cooled down in $\mathrm{H}_{2}$ to room temperature and degassed water containing 100 ppm of $\mathrm{NO}_{3}^{-}$as reactant was co-fed with $\mathrm{H}_{2}$ or $\mathrm{N}_{2}$ by means of a pneumatic pump and a mass flow controller, respectively. The catalytic performance (concentration of $\mathrm{NO}_{3}^{-}, \mathrm{NO}_{2}^{-}$and $\mathrm{NH}_{4}^{+}$) was evaluated offline by UV-Vis measurements. The $\mathrm{Cu}$ oxidation states and local geometry was determined in situ during the process using HERFD XANES at the $\mathrm{Cu}$ K-edge measured with the 5-crystal Johann spectrometer. The initial state of the catalyst was a $\mathrm{Pt}-\mathrm{Cu}$ or $\mathrm{Pd}-\mathrm{Cu}$ alloy. Segregation of the metal components occurred under reaction conditions especially for the $\mathrm{Pt}-\mathrm{Cu}$ system. Metallic and alloy phases were active for removal of nitrites and their concentration was highly dependent on the amount of hydrogen in the feed.

The flexibility on the high energy resolution fluorescence detection setup even for complex catalytic processes within high pressure autoclaves was demonstrated by Makosch et al. ${ }^{[35]}$ A specially designed autoclave reactor allowed the changes in the structure of supported gold catalyst to be followed during activation of a $\mathrm{Au} / \mathrm{CeO}_{2}$ precursor and catalytic hydrogenation of nitrobenzene. During the latter process only $\mathrm{Au}^{\circ}$ was determined to be present and is thus considered the active phase. ${ }^{[36]}$ Simultaneously to the registration of HERFD XANES at the $\mathrm{Au} \mathrm{L}_{3}$ edge the reactor allowed the conversion and selectivity to be monitored in situ using an integrated probe for attenuated total reflectance Fourier transform infrared (ATR-FTIR) spectroscopy measurements. The final example illustrates the capabilities of SuperXAS for the studies of industrially relevant catalytic processes under extreme conditions. The work of Dreher $e t$ $a l .{ }^{[30]}$ presents the design and performance of a novel high-temperature and highpressure continuous-flow reactor which allows for X-ray absorption spectroscopy and diffraction in supercritical water and other fluids under high pressure and temperature. The in situ cell consists of a tube

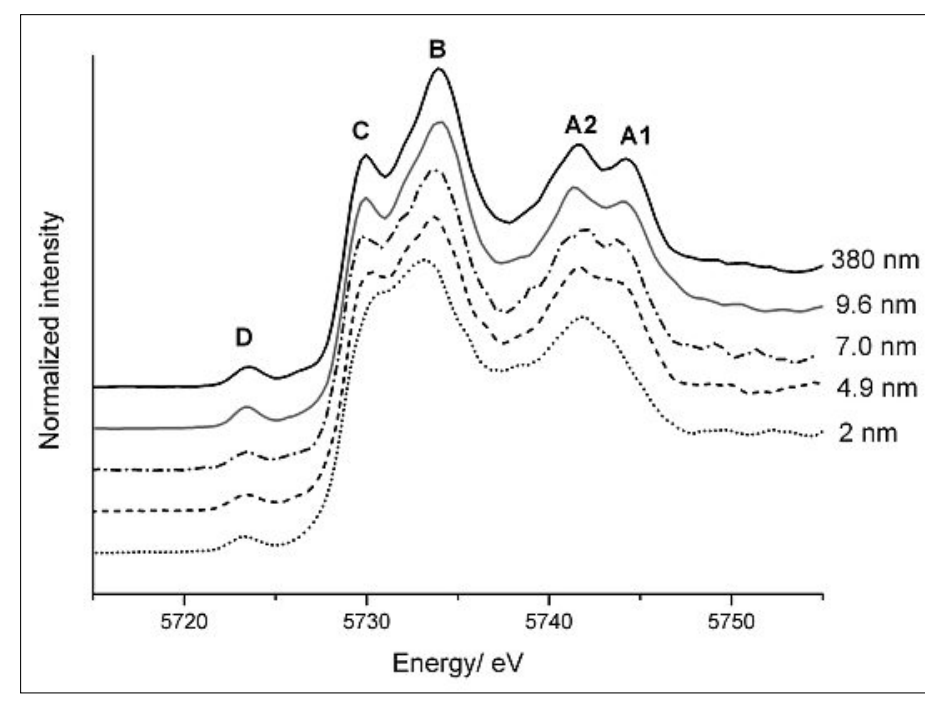

Fig. 7. Ce $L_{3}$ HERFD XANES spectra of ceria samples with different mean particles sizes compared to bulk ceria $\left(\mathrm{CeO}_{2} \mathrm{NIST}\right)$ and $\mathrm{Ce}_{2}\left(\mathrm{CO}_{3}\right)_{3} \cdot \mathrm{xH}_{2} \mathrm{O}$ standard. The arrows indicate the changes related to the decrease of the size. Reprinted with permission from ref. [33].

of polycrystalline aluminum nitride (AIN), which is tolerant to corrosive chemical media, and which is stable up to $500{ }^{\circ} \mathrm{C}$ and pressures up to $30 \mathrm{MPa}$. The performance of the reactor is demonstrated by recording extended X-ray absorption fine structure (EXAFS) spectra of a carbon-supported ruthenium $(\mathrm{Ru} / \mathrm{C})$ catalyst during the continuous hydrothermal gasification of ethanol in supercritical water (SCW) at $400{ }^{\circ} \mathrm{C}$ and $24 \mathrm{MPa}$.

\section{Conclusions}

The SNBL and SuperXAS beam lines are highly complementary in terms of X-ray energy range, experimental techniques based on hard X-rays, and orientation towards time resolved studies using multitechnique approaches when required. Both beam lines have excellent facilities for performing in situ and operando measurements under catalytically relevant conditions. These experimental facilities offer a large variety of X-ray spectroscopic and diffraction methods with enhanced chemical sensitivity and time-resolution, which are in particular suitable for the study of the dynamic structure of catalytic materials. As unique features, the SNBL beam line provides the users with very high energy XAS (above $35 \mathrm{keV}$ ), rarely available at synchrotrons, as well as a combination XAS/XRD/Raman spectroscopies in the same setup. As unique features, the SuperXAS beam line provides the users with sub-second time resolution using the QEXAFS setup and with high energy resolution XES and RIXS methods, whereas the combined XAS/XES/IR facility soon will be available. In addition, the staff at both beam lines provides expertise for users in the field of catalysis and complex catalytic setups for in situ and operando experiments using hard X-rays.
Received: July 5, 2012

[1] J.-D. Grunwaldt, J. Phys.: Conf. Ser. 2009, 190, 012151.

[2] D. Bazin, C. Mottet, G. Tréglia, J. Lynch, Appl. Surf. Sci. 2000, 164, 140; D. Bazin, in 'Nanotechnology in Catalysis', Ed. G. A. Somorjai, S. Hermans, B. Zhou, Kluwer Academic/Plenum Publishers, New York, 2003, p. 427.

[3] M. A. Newton, W. Van Beek, Chem. Soc. Rev. 2010, 39, 4845

[4] O. Balmes, R. van Rijn, D. Wermeille, A. Resta, L. Petit, H. Isern, T. Dufrane, R. Felici, Catalysis Today 2009, 145, 220.

[5] R. R. Chianelli, M. Perez De la Rosa, G. Meitzner, M. Siadati, G. Berhault, A. Mehta, J. Pople, S. Fuentes, G. Alonzo-Nuñez, L. A. Polette, J. Synchrotron Rad. 2005, 12, 129.

[6] G. J. Hutchings, J. Mater. Chem. 2009, 19, 1222.

[7] P. Glatzel, U. Bergmann, Coord. Chem. Rev. 2005, 249, 65 .

[8] S. N. Ehrlich, J. C. Hanson, A. Lopez Camara, L. Barrio, M. Estrella, G. Zhou, R. Si, S. Khalid, Q. Wang, Nucl. Instr. and Meth. A 2011, A649, 213.

[9] J. Singh, C. Lamberti, J. A. van Bokhoven, J. A. Chem. Soc. Rev. 2010, 39, 4754.

[10] W. Van Beek, O. V. Safonova, G. Wiker, H. Emerich, Phase Transitions 2011, 84, 726.

[11] R. Frahma, M. Nachtegaal, J. Stötzel, M. Harfouche, J. A. van Bokhoven, J.-D. Grunwaldt, AIP Conf. Proc. 2010, 1234, 25.

[12] http://www.esrf.eu/UsersAndSciencel Experiments/CRG/BM01/bm01-a

[13] E. Boccaleri, F. Carniato, G. Croce, D. Viterbo, W. van Beek, H. Emerich, Marco Milanesio, $J$. Appl. Cryst. 2007, 40, 684.

[14] Swiss-Norwegian beam lines (SNBL). Publications available from: http://www.esrf. fr/UsersAndScience/Experiments/CRG/BM01/ Publications.

[15] B. S. Clausen, G. Steffensen, B. Fabius, J. Villadsen, R. Feidenhans, H. Topsøe, J. Catal. 1991, 132, 524.

[16] S. Hannemann, M. Casapu, J.-D. Grunwaldt, P. Haider, P. Trüssel, A. Baiker, E. Welter, $J$. Synchrotron Rad. 2007, 14, 345.

[17] A. Longo, A. Balerna, F. d'Acapito, F. D'Anca, F. Giannici, L. F. Liotta, G. Pantaleo, A. Martorana, J. Synchrotron Rad. 2005, 12, 499.

[18] M. Rønning, N. E. Tsakoumis, A. Voronov, R. E. Johnsen, P.Norby, W. Van Beek, Ø. Borg, E. Rytter, A. Holmen, Catal. Today 2010, 155, 289. 
[19] J.-D. Grunwaldt, N. Van Vegten, A. Baiker, W. Van Beek, J. Phys.: Conf. Ser. 2009, 190, 012160 .

[20] J.-D. Grunwaldt, N. van Vegten, A. Baiker, Chem. Commun. 2007, 44, 4635.

[21] U. Deka, A. Juhin, E. A. Eilertsen, H. Emerich, M. A. Green, S. T. Korhonen, B. M Weckhuysen, Andrew M. Beale, J. Phys. Chem. C 2012, 116, 4809.

[22] M. Nachtegaal, M. Harfouche, M. Willimann, B. Meyer, E. De Boni, C. Frieh, O. Safonova, E. Kleymenov, J. Szlachetko, C. Koenig, G. Smolentsev, X. Liu, J.-D. Grunwaldt, J. Stoetzel, R. Frahm, J. Singh, R. Abela, J. A. van Bokhoven, J. Synchrotron Rad. submitted.

[23] E. Kleimenov, A. Bergamaschi, J. A. van Bokhoven, M. Janousch, B. Schmitt, M. Nachtegaal, J. Physics: Conference Series 2009, 190, 012035.

[24] E. Kleymenov, J. A. van Bokhoven, C. David, P. Glatzel, M. Janousch, R. Alonso-Mori, M Studer, M. Willimann, A. Bergamaschi, B. Henrich, M. Nachtegaal, Rev. Sci. Instrum. 2011, 82, 065107.
[25] J. Szlachetko, J. Sá, O. V. Safonova, G. Smolentsev, J. A. van Bokhoven, M. Nachtegaal, J. Electron. Spectrosc. Relat. Phenom. submitted.

[26] P. A. Kraft, A. Bergamaschi, C. Broennimann, P. Dinapoli, E. F. Eikenberry, B. Henrich, I. Johnson, A. Mozzanica, C. M. Schlepütz, P. R. Willmott, B. Schmitt, J. Synchrotron Rad. 2009 , 16,368 .

[27] O. V Safonova, M. Tromp, J. A. van Bokhoven, F. M. F de Groot, J. Evans, P. Glatzel, 2006, 110, 16162 .

[28] B. Schmitt, C. Brönnimann, E. F. Eikenberry, F. Gozzo, C. Hörmann, R. Horisberger, B. Patterson, Nucl. Instr. and Meth. A 2003, 501, 267.

[29] S. Hannemann, M. Casapu, J.-D. Grunwaldt, P. Haider, P. Trüssel, A. Baiker, E. Welter, $J$. Synchrotron Rad. 2007, 14, 345.

[30] M. Dreher, E. De Boni, M. Nachtegaal, J. Wambach, F. Vogel, Rev. Sci. Instrum 2012, accepted.
[31] J. Singh, M. Nachtegaal, E. M. C. Alayon, J. Stötzel, J. A. van Bokhoven, ChemCatChem 2010, 2, 653.

[32] S. Reimann, J. Stötzel, R. Frahm, W. Kleist, J.-D. Grunwaldt, A. Baiker, J. Am. Chem. Soc. 2011, 133, 3921.

[33] C. Paun, O. V. Safonova, J. Szlachetko, P Abdala, M. Nachtegaal, J. Sa, E. Kleymenov, A. Cervellino, F. Krumeich, J. A. van Bokhoven, J. Phys. Chem. C 2012, 116, 7312.

[34] J. Sá, N. Barrabés, E. Kleymenov, C. Lin, K. Föttinger, O. V. Safonova, J. Szlachetko, J. A van Bokhoven, M. Nachtegaal, A. Urakawa, G. A. Crespo, G. Rupprechter, Catal. Sci. Technol. 2012, 2, 794 .

[35] M. Makosch, C. Kartusch, J. Sa, R. B. Duarte, J. A. van Bokhoven, K. Kvashnina, P. Glatzel, D. L. A. Fernandes, M. Nachtegaal, E. Kleymenov, J. Szlachetko, B. Neuhold, K. Hungerbuhler Phys. Chem. Chem. Phys. 2012, 14, 2164.

[36] C. Kartusch, M. Makosch, J. Sá, J. A. van Bokhoven, Chem CatChem 2012, 4, 23. 